\title{
High dose intravitreal foscarnet in the treatment of cytomegalovirus retinitis in AIDS
}

\author{
Manuel Diaz-Llopis, Enrique España, Gonzalo Muñoz, Amparo Navea, Enrique Chipont, \\ Juan Cano, Jose L Menezo, Francisco J Romero
}

\begin{abstract}
The efficacy and tolerance of high dose intravitreal foscarnet for cytomegalovirus retinitis in patients with AIDS was studied. Foscarnet in a dose of $2400 \mu \mathrm{g}$ was injected directly into the vitreous of 11 patients ( 15 eyes). Five patients had active retinitis (eight eyes, $53 \cdot 3 \%$ ), and received a 3 week induction therapy of six injections as the first step. Six patients had initial inactive retinitis (seven eyes, $46.7 \%$ ), and received only maintenance therapy which consisted of a weekly injection. The main indications for intravitreal therapy were: myelosuppression, kidney toxicity, catheter related sepsis, or refusal of intravenous therapy. The patients were followed for a mean period of 16 weeks (range 8-28 weeks) and received a total of 304 injections. Vitreous foscarnet levels were measured by high performance liquid chromatography. After a 3 week course of induction therapy, complete resolution of the active retinitis was seen in $62 \cdot 5 \%$ ( $5 / 8$ cases), while $37 \cdot 5 \%$ ( $3 / 8$ cases) had partial resolution. No cases failed to respond or progress. The rate of relapse on maintenance therapy was 33\% (five of 15 eyes) by 20 weeks, and two of these eyes did not respond to reinduction and progressed in involvement of the macula or optic nerve. Neither important local complications nor intraocular drug toxicity were observed. Vitreous foscarnet levels in two different patients were 896 $\mu \mathrm{mol} / 1$ and $749 \mu \mathrm{mol} / \mathrm{l}$ at $223 / 4$ hours and $42 \frac{1}{2}$ hours after the injection. Intravitreal foscarnet appears to be a safe, effective, and useful alternative in patients with intolerance to intravenous antiviral therapy.
\end{abstract}

(Br f Ophthalmol 1994; 78: 120-124)

Department of

Pharmacology, and

Infectious Diseases, La

Fe University Hospital,

Valencia, Spain

M Diaz-Llopis

E España

G Muñoz

A Navea

E Chipont

J Cano

J L Menezo

Unit of Experimental

Toxicology and

Neurotoxicology,

Department of

Physiology, School of

Medicine, University of

Valencia, Spain

F J Romero

Correspondence to:

Dr Manuel Diaz-Llopis, Plaza

San Agustin 3-D-54, 46002

Valencia, Spain.

Accepted for publication

23 September 1993

Cytomegalovirus (CMV) retinitis is the most common opportunistic ocular infection in patients with AIDS. It has been reported in up to $45 \%$ of patients during the average 20 month course of survival of AIDS patients, ${ }^{1-7}$ and it often leads to blindness.

Only two virostatic drugs have been shown to be effective in CMV retinitis when administered systemically: foscarnet ${ }^{8-10}$ and ganciclovir, ${ }^{11-15}$ but severe side effects often limit their use and lead to their discontinuation. In such cases both drugs, when vitreally injected, proved to be effective alternatives in stopping the progression of retinitis. ${ }^{16-20}$.

Diaz-Llopis $e t a l^{20}$ have shown the efficacy of foscarnet in halting the progression of CMV retinitis in a patient after intravitreal doses of retinal toxicity in rabbits after intravitreal doses of up to $1000 \mu \mathrm{g}$.

We present a prospective study of courses of intravitreal foscarnet at a dose of $2400 \mu \mathrm{g}$ per injection. Provided there is no retinal toxicity, the higher dose is more desirable for both clinical and pharmacokinetic reasons, as it is believed that there is a correlation between intraocular concentration of foscarnet and the resulting virostatic effect.

\section{Patients and method}

GENERAL CHARACTERISTICS OF THE STUDY

This prospective open study was performed between September 1991 and January 1993. All patients met Centers for Disease Control criteria for the diagnosis of AIDS ${ }^{22}$ and were treated after obtaining permission from the ethics and clinical trials committee of $\mathrm{La} \mathrm{Fe}$ University Hospital. Informed consent was obtained from all patients. Table 1 summarises the clinical characteristics of these patients at the beginning of the study. Ophthalmic evaluations were performed at baseline and were repeated every week, including determination of best corrected visual acuity, slit-lamp biomicroscopy, indirect ophthalmoscopy, retinal drawings, and wide angle fundus photography. The location of CMV retinitis was identified by zones as described by Holland et al. ${ }^{23}$ Zone 1 extended up to $3000 \mu \mathrm{m}$ from the fovea and $1500 \mu \mathrm{m}$ from the optic disc (sight threatening area). Zone 2 was anterior to zone 1 up to the equator, and zone 3 was anterior to the equator.

\section{DIAGNOSTIC CMV RETINIS CRITERIA} $1200 \mu \mathrm{g}$. She $e t a l^{21}$ have reported the absence of
The diagnosis of CMV retinitis was made by indirect ophthalmoscopy. A characteristic lesion consisted of a zone of necrotising retinitis with more or fewer haemorrhages and vascular sheathing. Older healed areas showed an atrophic zone with fine pigment stippling and sometimes there were associated focal deposits of lipid or glial tissue.

\section{INCLUSION AND EXCLUSION CRITERIA}

Intravitreal foscarnet was used in two different conditions: (1) patients with active retinitis who refused systemic therapy; (2) patients with completely halted retinitis who were intolerant to the intravenous anti-CMV treatment (foscarnet or ganciclovir) because of kidney toxicity and/or myelosuppression. Renal toxicity was defined as an increase in baseline serum creatinine level 
higher than $50 \%$. Patients were considered neutropenic if they had an absolute neutrophil count of less than $1 \times 10^{9} / 1$ at any time during the 30 days before the enrolment. All types of CMV retinitis were treated. Those patients who showed evidence of active systemic CMV infection were ruled out. The patients who were on zidovudine continued on the same treatment after being included in the study.

\section{INTRAVITREAL TECHNIQUE}

Induction therapy followed by a maintenance treatment was only performed in patients with active retinitis. Induction therapy included an initial series of six injections, $2400 \mu \mathrm{g} / 0 \cdot 1 \mathrm{ml}$ per injection, given at intervals of 72 hours during the first 18 day period. Initial maintenance therapy was given to patients with inactive retinitis. Maintenance therapy consisted of a single weekly injection which was continued indefinitely. Recurrences were treated with repeated courses of induction therapy with a series of six injections given in 3 weeks. Patients were instructed to use topical tobramycin drops 2 days before and after each injection.

Foscarnet with $\mathrm{pH}$ of $7 \cdot 4$ prepared for intravenous infusion was provided by Schering Plough-Astra Spain Laboratories, Astra Group, Sweden. Each millilitre of the commercial solution contains $24 \mathrm{mg}$ ( $80 \mu \mathrm{mol})$ of foscarnet trisodium hexahydrate as well as both hydrochloric acid and water for injection. The isotonic solution was taken directly from the infusion bottle and was passed through a $0.22 \mu \mathrm{m}$ filter before injection.

Injections were performed on an outpatient basis with modifications of a previously described technique. ${ }^{24}$ Conjunctiva was cleaned with topical $5 \%$ povidone iodine solution. Topical $4 \%$ cocaine hydrochloride was used as an anaesthetic. We usually injected in the lower temporal quadrant but other areas were selected in those cases in which there was retinal necrosis in order to avoid iatrogenic retinal tears. The injections were performed with a 30 gauge needle attached to a tuberculin syringe containing $0.1 \mathrm{ml}$ of foscarnet $(2400 \mu \mathrm{g})$ solution. A point $4 \mathrm{~mm}$ posterior to the corneoscleral limbus was chosen, and the needle was passed with the needle tip directed towards the mid vitreous. When the needle tip was in the mid vitreous, foscarnet was slowly injected, then the needle was withdrawn from the eye and a cotton tip applicator was put on the injection point to avoid reflux. Pulsation of the central retinal artery was monitored after injection using indirect ophthalmoscopy.

\section{RESPONSE CRITERIA}

Determination of the efficacy of the treatment was based on the ophthalmoscopic appearance of retinal lesions. Visual acuity was not used as a response criterion. 'Progression or no response' was considered if the extent of the retinitis from

Table 1 Clinical characteristics of patients at the time of enrolment in the study

\begin{tabular}{|c|c|c|c|c|c|c|c|c|c|c|}
\hline No & $\begin{array}{l}\text { Sex } \\
\text { and } \\
\text { age }\end{array}$ & Risk factor & $\begin{array}{l}\text { Previous } \\
\text { systemic } \\
\text { antiviral } \\
\text { therapy }\end{array}$ & $\begin{array}{l}\text { Indication for } \\
\text { intravitreal } \\
\text { foscarnet }\end{array}$ & $\begin{array}{l}\text { Zidovudine } \\
\text { therapy }\end{array}$ & $\begin{array}{l}\text { AIDS before } \\
\text { intravitreal } \\
\text { therapy } \\
\text { (months) }\end{array}$ & Eye & Area & $\begin{array}{l}\text { Activity } \\
\text { of } \\
\text { retinitis }\end{array}$ & $\begin{array}{l}\text { Time between } \\
\text { systemic and } \\
\text { intravitreal } \\
\text { therapy (days) }\end{array}$ \\
\hline 1 & M 44 & Homosexual & Foscarnet & Kidney toxicity & - & 4 & \multirow{11}{*}{$\begin{array}{l}\mathbf{R} \\
\mathbf{R} \\
\mathbf{L} \\
\mathbf{R} \\
\mathbf{L} \\
\mathbf{R} \\
\mathbf{R} \\
\mathbf{L} \\
\mathbf{R} \\
\mathbf{L} \\
\mathbf{R} \\
\mathbf{L} \\
\mathbf{L} \\
\mathbf{R} \\
\mathbf{L}\end{array}$} & \multirow{11}{*}{$\begin{array}{l}2 / 3 \\
1 \\
1 \\
3 \\
3 \\
1 \\
1 \\
2 \\
1 \\
1 \\
1 \\
1 / 2 \\
2 / 3 \\
2 \\
1 / 2\end{array}$} & \multirow{3}{*}{$\begin{array}{l}\text { Inactive } \\
\text { Active } \\
\text { Active } \\
\text { Active } \\
\text { Active }\end{array}$} & 7 \\
\hline 2 & F 37 & Heterosexual & Ganciclovir & Myelotoxicity & - & 16 & & & & 27 \\
\hline 3 & M 34 & Drug misuser & - & Refuse & + & 5 & & & & 0 \\
\hline 4 & M 36 & Homosexual & Foscarnet & Kidney toxicity & + & 15 & & & Inactive & 9 \\
\hline 5 & M 34 & Heterosexual & Ganciclovir & Myelotoxicity & - & 12 & & & Inactive & 10 \\
\hline 6 & M 41 & Drug misuser & & Refuse & + & 24 & & & Active & 0 \\
\hline 7 & M 42 & Homosexual & Foscarnet & Kidney+ & - & 8 & & & $\begin{array}{l}\text { Inactive } \\
\text { Inactive }\end{array}$ & 6 \\
\hline 8 & M 29 & Homosexual & - & Refuse & - & 18 & & & $\begin{array}{l}\text { Active } \\
\text { Active }\end{array}$ & 0 \\
\hline 9 & F 39 & Heterosexual & Ganciclovir & Catheter sepsis & + & 6 & & & Inactive & 8 \\
\hline 10 & M 37 & Homosexual & Foscarnet & Kidney toxicity & - & 3 & & & Active & 29 \\
\hline 11 & M 30 & Homosexual & Ganciclovir & Myelotoxicity & + & 13 & & & Inactive & 8 \\
\hline
\end{tabular}

Table 2 Characteristics of intravitreal treatment with foscarnet

\begin{tabular}{|c|c|c|c|c|c|c|c|c|c|}
\hline \multirow[b]{2}{*}{ No } & \multirow[b]{2}{*}{ Eye } & \multicolumn{2}{|c|}{ Visual acuity } & \multirow[b]{2}{*}{$\begin{array}{l}\text { Number of } \\
\text { injections }\end{array}$} & \multirow{2}{*}{$\begin{array}{l}\text { Type of } \\
\text { intravitreal } \\
\text { therapy }\end{array}$} & \multirow[b]{2}{*}{$\begin{array}{l}\text { Grade of } \\
\text { response }\end{array}$} & \multirow[b]{2}{*}{$\begin{array}{l}\text { Recurrence } \\
\text { (months) }\end{array}$} & \multirow{2}{*}{$\begin{array}{l}\text { Foscamet } \\
\text { follow up } \\
\text { (weeks) }\end{array}$} & \multirow[b]{2}{*}{$\begin{array}{l}\text { Current } \\
\text { status }\end{array}$} \\
\hline & & Initial & Final & & & & & & \\
\hline 1 & $\mathbf{R}$ & $20 / 25$ & $20 / 25$ & 11 & Maintenance & Partial & - & 8 & Deceased \\
\hline 2 & $\begin{array}{l}\vec{R} \\
\mathrm{~L}\end{array}$ & $\begin{array}{l}20 / 50 \\
20 / 80\end{array}$ & $\begin{array}{l}\text { LP } \\
\text { NLP }\end{array}$ & $\begin{array}{l}27 \\
27\end{array}$ & $\begin{array}{l}\text { Induction+ } \\
\text { maintenance }\end{array}$ & $\begin{array}{l}\text { Partial } \\
\text { Partial }\end{array}$ & $\begin{array}{l}3 \\
3\end{array}$ & 20 & Deceased \\
\hline 3 & $\mathbf{R}$ & $\begin{array}{l}20 / 20 \\
20 / 30\end{array}$ & $20 / 20$ & 31 & Induction+ & Complete & - & 28 & Alive \\
\hline $\begin{array}{l}4 \\
5\end{array}$ & $\mathbf{R}$ & $20 / 60$ & $\begin{array}{l}20 / 60 \\
20 / 100\end{array}$ & 21 & Maintenance & Complete & - & $\begin{array}{l}18 \\
10\end{array}$ & $\begin{array}{l}\text { Deceased } \\
\text { Alive }\end{array}$ \\
\hline 6 & L & $20 / 30$ & $20 / 30$ & 19 & $\begin{array}{l}\text { Induction + } \\
\text { maintenance }\end{array}$ & Complete & - & 16 & Deceased \\
\hline 7 & $\begin{array}{l}\mathbf{R} \\
\mathbf{L}\end{array}$ & $\begin{array}{l}20 / 200 \\
20 / 80\end{array}$ & $\begin{array}{l}\text { CF } \\
20 / 200\end{array}$ & $\begin{array}{l}22 \\
22\end{array}$ & Maintenance & $\begin{array}{l}\text { Partial } \\
\text { Partial }\end{array}$ & $\begin{array}{l}4 \\
4\end{array}$ & 19 & Deceased \\
\hline 8 & $\begin{array}{l}\mathbf{R} \\
\mathbf{L}\end{array}$ & $\begin{array}{l}20 / 40 \\
20 / 60\end{array}$ & $\begin{array}{l}20 / 30 \\
20 / 30\end{array}$ & $\begin{array}{l}11 \\
11\end{array}$ & $\begin{array}{l}\text { Induction }+ \\
\text { maintenance }\end{array}$ & $\begin{array}{l}\text { Complete } \\
\text { Complete }\end{array}$ & - & 8 & Alive \\
\hline 9 & $\mathrm{~L}$ & $20 / 30$ & $20 / 30$ & 11 & Maintenance & Complete & - & 8 & Deceased \\
\hline 10 & $\overline{\mathbf{R}}$ & $20 / 50$ & $20 / 100$ & 30 & $\begin{array}{l}\text { Induction + } \\
\text { maintenance }\end{array}$ & Partial & 5 & 25 & Deceased \\
\hline 11 & $\mathrm{~L}$ & $20 / 200$ & $20 / 400$ & 17 & Maintenance & Complete & - & 14 & Alive \\
\hline
\end{tabular}

$L P=$ light perception; $N L P=$ no light perception; $C F=$ counting fingers. 
the onset of the treatment was an advance of 750 $\mu \mathrm{m}$ or more of any pre-existing CMV lesion or development of new retinal foci. An initial progression during induction therapy in the first 10 days could be seen in the cases with a good response and was not considered a real sign of progression. 'Complete response or resolution' was defined as arresting the progression of necrosing retinitis together with resolution of retinal opacification, haemorrhage, and vasculitis. We also considered cases of initial inactive retinitis without signs of reactivation during the treatment to be a complete response. 'Partial response or stabilisation' was defined as a lack of progression over healthy retina or a development of new foci. We also considered to be partial response the cases of resolution of the retinitis with persistence of oedema and opacification along the border. 'Recurrence or reactivation' was defined as the presence of new lesions, or opacification along the border of a previously complete inactive lesion.

\section{VITREOUS SAMPLES AND FOSCARNET LEVELS}

Two samples of vitreous were obtained during maintenance therapy from two different patients (Nos 2 and 10) at 223/4 and $42 \frac{1}{2}$ hours after the injection. Special informed consent was obtained from these two patients. Vitreous aspiration was performed under retrobulbar anaesthesia using a 21 gauge needle with prior sclerotomy. All vitreous samples were frozen immediately at $-20^{\circ} \mathrm{C}$ until analysis via a high performance liquid chromatography assay with electrochemical detection and a lower limit of detection of $33 \mu \mathrm{mol} / 1 .{ }^{25}$

\section{Results}

Table 2 summarises the efficacy of the treatment. Eleven patients (15 eyes) were studied and followed between 8 to 28 weeks (mean 16 weeks). Six were homosexual men, two were male injecting drug users, and three were heterosexual partners of seropositive subjects. Mean age was 36.6 years (range 29 to 44 years). Diagnosis of AIDS preceded the diagnosis of CMV retinitis by a mean of 11.2 months (range 4 to 24 months). In the last follow up we found that seven of the 11 patients had died from opportunistic infections.

Cytomegalovirus retinitis was unilateral in seven patients $(63.6 \%)$ and bilateral in four patients $(36.4 \%)$. At recruitment, retinitis affected only zone 1 in seven out of the 15 eyes, zone 2 in two eyes, zone 3 in two eyes, both zones 2 and 3 in two eyes, and both zones 1 and 2 in two eyes. A total of 304 injections were given. Bilateral injections were given when needed. The main indications for intravitreal therapy were: myelosuppression $(27 \cdot 2 \%)(3 / 11)$, myelosuppression plus kidney toxicity $(9 \%)(1 / 11)$, kidney toxicity alone $(27 \cdot 2 \%)(3 / 11)$, refusal of intravenous therapy $(27 \cdot 2 \%)(3 / 11)$, and catheter related sepsis $(9 \%)(1 / 11)$. None of the patients with unilateral retinitis had developed CMV retinitis in the other eye at the last follow up. Active retinitis showed no progression in all eyes 3 weeks after the beginning of intravitreal treat- ment. Complete halt and replacement by atrophic retina occurred within 5 to 9 weeks. Among 15 eyes, eight received induction plus maintenance therapy and seven received only maintenance therapy. Reinduction was made in five of 15 eyes $(33.3 \%)$ because of retinitis reactivation during maintenance therapy. In two of these five eyes (13.3\%) CMV retinitis progressed leading to blindness by involvement of macula or optic nerve. No intraocular complications such as retinal detachment, intravitreal haemorrhage, endophthalmitis, or cataract were observed during intravitreal therapy.

The concentration of foscarnet in the vitreous was $896 \mu \mathrm{mol} / 1$ and $749 \mu \mathrm{mol} / \mathrm{l}$ at $223 / 4$ and $421 / 2$ hours respectively after the injection of $8 \mu \mathrm{mol}$ $(2400 \mu \mathrm{g})$ in $0 \cdot 1 \mathrm{ml}$

\section{Discussion}

Several studies using intravenous treatment with either foscarnet or ganciclovir have achieved a similar degree of success in terms of the initial response rate of CMV retinitis in AIDS patients. Nevertheless, a high incidence of side effects, especially myelotoxicity with ganciclovir and kidney toxicity with foscarnet, results in discontinuation of therapy in almost one third of patients. Intravitreal administration has been shown to be an effective alternative in these patients. ${ }^{16-20}$

Local intravitreal therapy has two main disadvantages compared with systemic treatment: a poorer survival rate and a greater incidence of progression to bilateral CMV retinitis. ${ }^{1317242627}$ The main advantages of intravitreal therapy are: (i) it avoids the necessity of hospitalisation during induction intravenous therapy, (ii) it eliminates the high incidence of sepsis associated with chronic home administration during maintenance intravenous treatment, and (iii) it improves patient quality of life. An alternative to multiple repeated intravitreal injections is the surgical implantation of an intravitreal device, which delivers ganciclovir intraocularly over approximately 4 to 5 months. This implant has demonstrated resolution of the CMV retinitis in all cases in a long term clinical study, ${ }^{28}$ but with a high rate of complications, such as intraoperative vitreous haemorrhage and suprachoroidal implantation of the device.

Since foscarnet (trisodium phosphonoformate hexahydrate) and ganciclovir are virostatic agents, they must be administered continuously for life so as to avoid the progression of CMV infection. Compared with ganciclovir, foscarnet has the advantage of in vitro activity against both HIV and CMV. The drug has been shown to be effective in ganciclovir resistant CMV retinitis. ${ }^{29}$ When compared with intravenous administration, intravitreal foscarnet has the advantage of lacking renal toxicity which occurs in as many as $46 \%$ of patients during systemic treatment. ${ }^{30}$

Encouraged by our initial results with low dose intravitreal foscarnet, ${ }^{20}$ we have treated a series of 11 patients with multiple high dose intravitreal injections. Because of the virostatic nature of foscarnet, all patients remained on maintenance therapy. CMV retinitis showed no progression in all eyes 3 weeks after induction 
therapy began. Resolution of exudative borders occurred within 5 to 6 weeks, and a complete area of atrophic retina could be seen as late as 8 to 10 weeks after the onset of the treatment. Despite successful induction and maintenance therapy, we have found evidence of relapse in five out of 15 eyes while on maintenance therapy (33.3\% at 20 weeks). All relapses presented as an insidious active front at the margin of the scarred lesion ('smouldering'), without the appearance of new 'brushfire' lesions. Three responded to a second course of induction therapy.

Considered as a whole, these results showed clinical efficacy of intravitreal foscarnet similar to anti-CMV therapies previously reported, but with a lower relapse rate than those previously reported with intravitreal ganciclovir $(33 \%$ to $45 \%$ at 8 to 12 weeks of maintenance therapy). ${ }^{17} 1924$ This difference may be attributed to the proved development of resistance in patients treated with ganciclovir, ${ }^{31}$ which has not been reported with foscarnet. With intravenous foscarnet, a better response to the treatment seemed to be observed when zidovudine was added. ${ }^{10}$ In this study the percentage of patients who responded to intravitreal foscarnet therapy with a complete resolution was higher in the group treated with zidovudine than in the group treated with foscarnet alone (without zidovudine).

Our experience has demonstrated that multiple intravitreal injections are well tolerated. Good intraocular tolerance is shown by the visual acuity remaining at $20 / 30$ or more in seven eyes throughout the follow up period. The absence of retinal detachments in the present study shows a substantially lower incidence of this complication than in other clinical studies using intravitreal ganciclovir injections ${ }^{24}$ or an intravitreal device. ${ }^{28}$ Although retinal detachments have been attributed to microbreaks located in the porous junction of normal and atrophic retina, vitreous anomalies induced by ganciclovir $(\mathrm{pH}$ $10 \cdot 14)$ may be a contributing factor. ${ }^{24}$ The $\mathrm{pH}$ of foscarnet $(7 \cdot 4)$ which is closer to the physiological value could be an added advantage. Previous series using intravitreal therapy have reported an incidence of endophthalmitis of $0.4 \%$ to $0.6 \% .{ }^{17}{ }^{18}$ The lack of intraocular infections in our series, consistent with that previously reported, ${ }^{24}$ could be attributed to the use of povidone iodine eyedrops before the injection.

Henry et $a l^{16}$ have reported that the vitreal levels of ganciclovir remain above the $50 \%$ inhibitory concentration of most human CMV strains for a period of about 62 hours after a single $200 \mu \mathrm{g}$ injection. Cochereau-Massin et $\mathrm{al}^{24}$ have reported no differences in clinical efficacy using $400 \mu \mathrm{g}$ per injection instead of $200 \mu \mathrm{g}$. The mean $50 \%$ inhibitory value of foscarnet for most strains of human CMV and for the HIV are $271 \mu \mathrm{mol} / /^{32}$ and $10-25 \mu \mathrm{mol} / /^{30}$ respectively. Diaz-Llopis et $a l^{20}$ have reported a vitreous level of $292 \mu \mathrm{mol} / \mathrm{l}$ at $491 / 2$ hours after the intravitreal injection of $1200 \mu \mathrm{g}$ of foscarnet. Although the dose used in this series is twice the amount used in a previous study, the intravitreal levels of foscarnet found $(749 \mu \mathrm{mol} / 1$ at $421 / 2$ hours after injection of $2400 \mu \mathrm{g}$ ) are propor- tional to those previously described. Since these data were from different patients, no pharmacokinetic curve could be produced.

In conclusion, intravitreal foscarnet is a safe and effective local therapy for CMV retinitis in AIDS patients when intravenous administration of antiviral agents is not recommended. The $2400 \mu \mathrm{g}$ dosage does not cause clinical toxicity and has a better intravitreal absorption than intravitreal ganciclovir. Since intravitreal therapy does not control systemic infection, a close follow up is required to detect extraocular CMV involvement.

Presented in part at the Ocular Immunology and Microbiology Group Annual Meeting, Dallas, November, 1992.

This study was supported in part by the following grants: Fondo de Investigaciones Sanitarias de la Seguridad Social Grant (FISS) number $92 / 0403$ and Dirección General de Investigación, Científic y Técnica Grant (DGICYT) number PM 92-0146.

The authors and authors' families have no commercial or property interest in foscarnet and have received no financial remuneration from the Astra Corporation.

The authors are grateful to Dr Tarek Az for his excellent technical help and assistance.

1 Friedman AH. The retinal lesions of the acquired immune deficiency syndrome. Trans Am Ophthalmol Soc 1984; 82: 447-91.

2 Holland GN, Pepose JS, Pettit TH, Gottlieb MS, Yee RD, Foos RY. Acquired immune deficiency syndrome. Ocular manifestations. Ophthalmology 1983; 90: 859-73.

3 Pepose JS, Holland GN, Nestor MS, Cochran AJ, Foos RY. Acquired immune deficiency syndrome. Pathogenic mechanisms of ocular disease. Ophthalmology 1985; 92: 47284.

4 Palestine AG, Rodrigues MM, Macher AM, Chan CC, Lane HC, Fauci AS, et al. Ophthalmic involvement in acquired immunode

5 Freeman WR, Lerner CW, Mines JA, Lash RS, Nadel AJ, Starr MB, et al. A prospective study of the ophthalmologic findings in the acquired immune deficiency syndrome. $A m \mathcal{F}$ Ophthalmol 1984; 97: 133-42.

6 Holland GN, Sison RF, Jatulis DE, Haslop MG, Sakamoto MJ, Wheeler NC, and UCLA Cytomegalovirus Retinopathy Group. Survival of patients with the acquired immune deficiency syndrome after development of cytomegalovirus retinopathy. Ophthalmology 1990; 97: 204-11.

7 Holland GN, Sakomoto MJ, Hardy D, Sidikaro Y, Kreiger AE, Frenkel LM, and the UCLA CMV Retinopathy Study Group. Treatment of cytomegalovirus retinopathy in Group. Treatment of cytomegalovirus retinopathy in patients with acquired immuno

8 Jacobson MA, O'Donnell JJ, Mills J. Foscarnet treatment of cytomegalovirus retinitis in patients with acquired immunodeficiency syndrome. Antimicrob Agents Chemother 1989; 33: 736-41.

9 Fanning MM, Read SE, Benson M, Vas S, Rachlis A, Kozousek V, et al. Foscarnet therapy of cytomegalovirus retinitis in AIDS. 7 Acquir Immune Defic Syndr 1990; 3: 472-9.

10 Lehoang $P$, Girard B, Robinet $M$, Marcel P, Zazoun L, Matheron S, et al. Foscarnet in the treatment of cytomegalovirus retinitis in acquired immune deficiency syndrome. Ophthalmology 1989; 96: 865-74.

11 Palestine AG, Stevens G, Lane HC, Masur H, Fujikawa LS, Nussenblatt RB, et al. Treatment of cytomegalovirus retinitis with dihydroxy propoxymethyl guanine. Am $\mathcal{F}$ Ophthalmol 1986; 101: 95-101.

12 Rosecan LR, Stahl-Bayliss CM, Kalman CM, Laskin OL. Antiviral therapy for cytomegalovirus retinitis in AIDS with dihydroxy propoxymethyl guanine. Am $\mathcal{F}$ Ophthalmol 1986; 101: 405-18.

13 Henderly DE, Freeman WR, Causey DM, Rao NA. Cytomegalovirus retinitis and response to therapy with ganciclovir. Ophthalmology 1987; 94: 425-34.

14 Holland GN, Sidikaro Y, Kreiger AE, Hardy D, Sakamoto MJ, Frenkel LM, et al. Treatment of cytomegalovirus retinopathy with ganciclovir. Ophthalmology 1987; 94: 81523.

15 Jabs DA, Newman C, De Bustros S, Polk BF. Treatment of cytomegalovirus retinitis with ganciclovir. Ophthalmology 1987; 94: 824-30

16 Henry K, Cantrill H, Fletcher C, Chinnock BJ, Balfour HH Use of intravitreal ganciclovir (dihydroxy propoxymethyl guanine) for cytomegalovirus retinitis in a patient with AIDS. Am f Ophthalmol 1987; 103: 17-23.

17 Heinemann MH. Long-term intravitreal ganciclovir treatment of cytomegalovirus retinopathy. Arch Ophthalmol 1989; 107: 1767-72.

18 Cantrill HL, Henry K, Melroe NH, Knobloch WH, Ramsay $\mathrm{RC}$, Balfour $\mathrm{HH}$. Treatment of cytomegalovirus retinitis with intravitreal ganciclovir. Long-term results. Ophthal mology 1989; 96: 367-74. 
19 Ussery FM III, Gibson SR, Conklin RH, Piot DF, Stool EW, Conklin AJ. Intravitreal ganciclovir in the treatment of AIDS-associated cytomegalovirus retinitis. Ophthalmology 1988; 95: 640-8.

20 Diaz-Llopis M, Chipont E, Sanchez S, España E, Navea A Menezo JL. Intravitreal foscarnet for cytomegalovirus retinitis in a patient with acquired immune deficiency retinitis in a patient with acquired immune

21 She Sh, Peyman GA, Schulman JA. Toxicity of intravitreal injection of foscarnet in the rabbit eye. Int Ophthalmol 1988; 12: $151-4$.

22 Centers for Disease Control. Revision of the CDC surveillance case definition for acquired immunodeficiency syndrome. $M M W R$ (Suppl 1S) 1987; 36: 1-15.

23 Holland GN, Buhles WC, Mastre B, Kaplan HJ, and UCLA CMV Retinopathy Study Group. A controlled retrospective study of ganciclovir treatment for cytomegalovirus retinopathy: use of a standardized system for the assessment of pathy: use of a standardized system for the assessment
disease outcome. Arch Ophthalmol 1989; 107: 1759-66.

24 Cochereau-Massin I, Lehoang P, Lautier-Frau M, Zazoun L, Marcel P, Robinet $M$, et al. Efficacy and tolerance of intravitreal ganciclovir in cytomegalovirus retinitis in acquired immune deficiency syndrome. Ophthalmology 1991; 98: 1348-55.

25 Hassanzadeh MK, Aweeka FT, Wu S, Jacobson MA Gambertoglio JG. Determination of phosphonoformic acid in human plasman and urine by high-performance liquid chromatography with electrochemical detection. f Chromatogr 1990; 525: 133-40.

26 Jabs DA. Treatment of cytomegalovirus retinitis 1992. Arch Ophthalmol 1992; 110: 185-7.

27 Gross JG, Bozzette SA, Matheus WC, Spector SA Abramson IA, McCutchan JA, et al. Longitudinal study of cytomegalovirus retinitis in acquired immune deficiency syndrome. Ophthalmology 1990; $97: 681-6$.

28 Sanborn GE, Anand R, Torti RE, Nightingale SD, Cal SX, Yates B, et al. Sustained-release ganciclovir therapy for treatment of cytomegalovirus retinitis. Use of an intravitreal device. Arch Ophthalmol 1992; 110: 188-95.

29 Jacobson MA, Drew WL, Feinberg J, O'Donell JJ, Whitmore PV, Miner RD, et al. Foscarnet therapy for ganciclovir-resistant cytomegalovirus retinitis in patients with AIDS. F Infect Dis 1991; 163 1348-51.

30 Chrisp P, Clissold SP. Foscarnet: a review of its antiviral activity, pharmacokinetic properties and therapeutic use in immunocompromised patients with cytomegalovirus retinitis. Drugs 1991; 41: 104-9.

31 Drew WL, Miner RC, Busch DF, Follanshee SE, Gullet J, Mehalko SG, et al. Prevalence of resistance in patients receiving ganciclovir for serious $\mathrm{CMV}$ infection. $\mathcal{F}$ Infect $D$ is 1991; 163: 716-9.

32 Wahren B, Öberg B. Reversible inhibition of cytomegalovirus replication by phosphonofornate. Intervirology 1980; 14: 7-15. 